\title{
ENTONACIÓN DE LOS ENUNCIADOS ASEVERATIVOS EN EL ESPAÑOL DE TUXTLA GUTIÉRREZ, CHIAPAS
}

\section{INTONATION PATTERNS OF STATEMENTS IN THE SPANISH OF TUXTLA GUTIÉRREZ, CHIAPAS}

\author{
Erika Mendoza Vázouez \\ Universidad Nacional Autónoma de México \\ emvazquez03@gmail.com
}

RESUMEN: El objetivo principal de este artículo es describir las configuraciones tonales de los enunciados aseverativos en el español de Tuxtla Gutiérrez, Chiapas. El análisis integra tres fuentes de datos: formal, semiespontáneo y espontáneo. Los resultados muestran: $i$ ) el acento nuclear $\mathrm{L}+(i) \mathrm{H}^{*}$, favorecido por los hombres y el estilo espontáneo, y ii) el alineamiento temprano del primer pico tonal, favorecido por el grupo de edad correspondiente a adultos y el nivel de instrucción bajo. La descripción sociolingüística y geolingüística de esta variedad busca contribuir con nuevos datos en el ámbito de la dialectología prosódica de México.

Palabras clave: prosodia; foco amplio; alineamiento temprano; acento nuclear; español de México.

Abstract: The main objective of this paper is to describe the tonal configurations of the assertive statements in the Spanish of Tuxtla Gutiérrez, Chiapas. The analysis integrates three data sources: formal, semi-spontaneous and spontaneous. The findings show: $i$ ) the nuclear pitch accent $\mathrm{L}+(i) \mathrm{H}^{*}$, favoured by men and by the spontaneous style, and ii) the early alignment of the first tonal peak, favoured by the adult age group and those with a low level of instruction. By offering a sociolinguistic and geolinguistic description of this variety this paper seeks to provide new data in the field of prosodic dialectology in Mexico.

Keywords: prosody; broad focus statements; early-peak alignment;

nuclear pitch accent; Mexican Spanish.

Recepción: 7 de agosto de 2017; aceptación: 15 de marzo de 2018. 
INTRODUCCIÓN*

Desde una perspectiva dialectológica, se ha mencionado que la zona de Chiapas -estado donde se ubica el municipio de Tuxtla Gutiérrez ${ }^{1}$ - muestra rasgos lingüísticos coincidentes con la región de Centroamérica (Henríquez Ureña 1921, 1938), y se le ha atribuido un carácter de conservador y rural (Martín Butragueño 2014). La caracterización como una zona dialectal aislada (Lope Blanch 1996) se origina a partir de la identificación de rasgos particulares como el voseo, que no ha sido registrado en otras variedades del español mexicano. De ahí que en estudios de dialectología perceptual (Serrano ms.), el uso del voseo haya sido pista importante para la identificación de la variedad chiapaneca como independiente.

En otras clasificaciones se ha propuesto un área del español mayense-centroamericano, que incluye el español yucateco y el estado de Chiapas (Moreno Fernández 2009). Esta división se basa en la distinción entre áreas de pueblos nuevos -surgidos por fusión de culturas-y pueblos testimonio -que abarcan la zona de América Central y los estados de Yucatán y Chiapas en el sur de México. Cabe mencionar que esta subdivisión del área mayense-centroamericana apartaría de México la zona de Chiapas y la agruparía con Centroamérica.

Si bien el área de Chiapas posee afinidades lingüísticas con los países de Centroamérica, y a la vez con la variedad de la península de Yucatán (Martín Butragueño 2014a), las diferencias que se establecen en los niveles fónico, sintáctico y léxico

* Investigación realizada gracias al Programa UNAM-DGAPA-PAPIIT IA400817 "Configuraciones tonales del español de México: bases para una caracterización geoprosódica”. Agradezco los valiosos comentarios recibidos en el Seminario de Presentación y Análisis de datos, coordinado por la Dra. Cecilia Rojas, y en el Seminario Permanente del Centro de Lingüística Hispánica en el IIFL-UNAM. Asimismo, quiero expresar mi gratitud hacia los dos lectores anónimos, cuyos comentarios y observaciones enriquecieron este trabajo. De la misma manera, agradezco a la Dra. Leonor Orozco por su asesoría en el análisis estadístico y por sus comentarios a una versión previa de este trabajo. Cualquier error u omisión en el texto es responsabilidad mía.

${ }^{1}$ El estado de Chiapas, en el sureste de México, antiguamente formó parte de la Capitanía General de Guatemala. Colinda al norte con el estado de Tabasco, al sur con el Océano Pacífico y al este con Guatemala. El municipio de Tuxtla Gutiérrez colinda al norte con el Río Grijalva y Chiapa de Corzo y al sur con Suchiapa y Ocozocoautla de Espinosa. 
respecto a esta última variedad, y a las del resto de México, han contribuido a la delimitación de esta zona como un área aislada o independiente de las demás entidades del país².

A pesar del reconocimiento de rasgos lingüísticos en la zona de Chiapas -presencia del voseo, elementos léxicos, etc.-, actualmente se carece de trabajos que permitan dar cuenta del estado de esta variedad del español en el ámbito dialectal y sociolingüístico (Martín Butragueño 2014a). Teniendo en mente este panorama, en el presente trabajo se busca contribuir con la descripción de rasgos prosódicos de la variedad de Tuxtla Gutiérrez, con miras a establecer -en un futuro- una propuesta de geoprosodia o dialectología entonativa del español de México.

El propósito de esta investigación es describir las configuraciones tonales registradas en los enunciados aseverativos en el español de Tuxtla Gutiérrez, Chiapas; dicha descripción se concentra en enunciados aseverativos de foco amplio. Se establecerá una comparación en el eje de estratificación social y geolingüístico (con la variedad del español mexicano central y la ciudad de Mérida, Yucatán). El análisis propuesto se emprende desde una perspectiva de corte realista (Martín Butragueño 2011), que emplea datos de diversas fuentes o estilos de habla: formal, semiespontáneo y espontáneo, y toma como unidad de análisis la comunidad de habla.

La estructura del trabajo es la siguiente: en el primer apartado se mencionan las características de los enunciados aseverativos en español; en el segundo, se expone la metodología utilizada para el análisis de los datos; en el tercero, se presenta el repertorio de acentos tonales y tonos de juntura registrados en la variedad de Tuxtla; luego, se ofrecen los resultados de las configuraciones nucleares y prenucleares. Finalmente, se presentan las conclusiones y líneas de trabajo para el futuro.

${ }^{2}$ Uno de los aspectos que es importante considerar es la vitalidad de las lenguas indígenas en el estado de Chiapas. En el censo de 2010 (INEGI), se reportó un total de 1141499 hablantes (mayores de 5 años) de alguna lengua indígena. Las cuatro lenguas con mayor número de hablantes en el estado son el tzeltal (461 236), tzotzil (417 462), chol (191947) y zoque (53 839). Otras lenguas que también se hablan en la entidad son el lacandón, tojolabal, q'atok, Q'anjob'al, Akateko, Jakalteko, Chuj, K'iche', Teko, Mam (INALI 2008). 
En la tradición entonológica del español (Navarro Tomás 1944; Quilis 1993) se han reconocido diferentes pistas prosódicas que caracterizan la producción de los enunciados aseverativos ${ }^{3}$, a saber: $i$ ) la curva melódica comienza en un tono medio y muestra una elevación progresiva a lo largo de la sílaba tónica, que se extiende -y culmina su pico tonal-en la postónica; ii) a partir de la culminación del primer pico tonal ocurre un descenso a lo largo del cuerpo del enunciado; iii) el descenso continúa hasta el tonema -acento nuclear más juntura del enunciado- que aporta el sentido de finalidad al enunciado.

En términos del modelo métrico-autosegmental y el sistema de notación prosódica Sp_ToBI, el inicio en tono medio, la elevación progresiva de la curva melódica y su culminación en la sílaba postónica corresponden al acento tonal $\mathrm{L}+>\mathrm{H}^{*}-$ pico tonal desplazado ${ }^{4}$. El descenso en el tonema del enunciado se describiría con la configuración L* L\% (véase infra Figura 1). Esta descripción coincide con la configuración propuesta para los enunciados aseverativos de foco amplio (broad focus statements) registrados en la variedad de la Ciudad de México, con el desplazamiento del primer pico tonal $\mathrm{L}+>\mathrm{H}^{*}$ y el tonema $\mathrm{L}^{*}$ L\% (De-la-Mota et al. 2010) ${ }^{5}$.

En el ámbito de la entonación en México, una de las variedades que cuenta con mayor descripción corresponde a la de la Ciudad de México. Martín Butragueño (2004, 2006 y 2011) ha descrito un patrón de entonación circunflejo, que consiste en un ascenso prominente en la sílaba tónica y un descenso en la postónica, es decir $\mathrm{L}+i \mathrm{H}^{*} \mathrm{~L} \%$. En la Figura 1 se muestran las dos realizaciones de un enunciado aseverativo de foco amplio, con la configuración descendente $\mathrm{L} * \mathrm{~L} \%$ y con la for-

${ }^{3}$ En los trabajos clásicos de entonación del español se utiliza el término de "entonación declarativa" (Navarro Tomás 1944; Quilis 1993); en trabajos recientes se hace referencia a entonación de enunciados declarativos de foco amplio (Prieto \& Roseano 2010; Frota \& Prieto 2015).

${ }^{4}$ Véase el apartado de resultados (infra) para la descripción detallada de los acentos tonales. La notación L+>H* corresponde a la versión de Sp_ToBI propuesta por Estebas Vilaplana y Prieto (2008).

${ }_{5}^{5}$ La configuración nuclear $\mathrm{L}^{*} \mathrm{~L} \%$ también se ha documentado en los enunciados aseverativos de foco amplio (broad focus statements) de diferentes variedades del español: castellano, de Cantabria, Canarias, Ecuador y Buenos Aires (Prieto \& Roseano 2010). 


\section{Figura 1}

Oscilograma, espectrograma y curva melódica del enunciado

El niño no ha llegado. Configuración nuclear $L^{*} L \%$ (arriba) y $L+j H^{*} L \%$ (abajo)
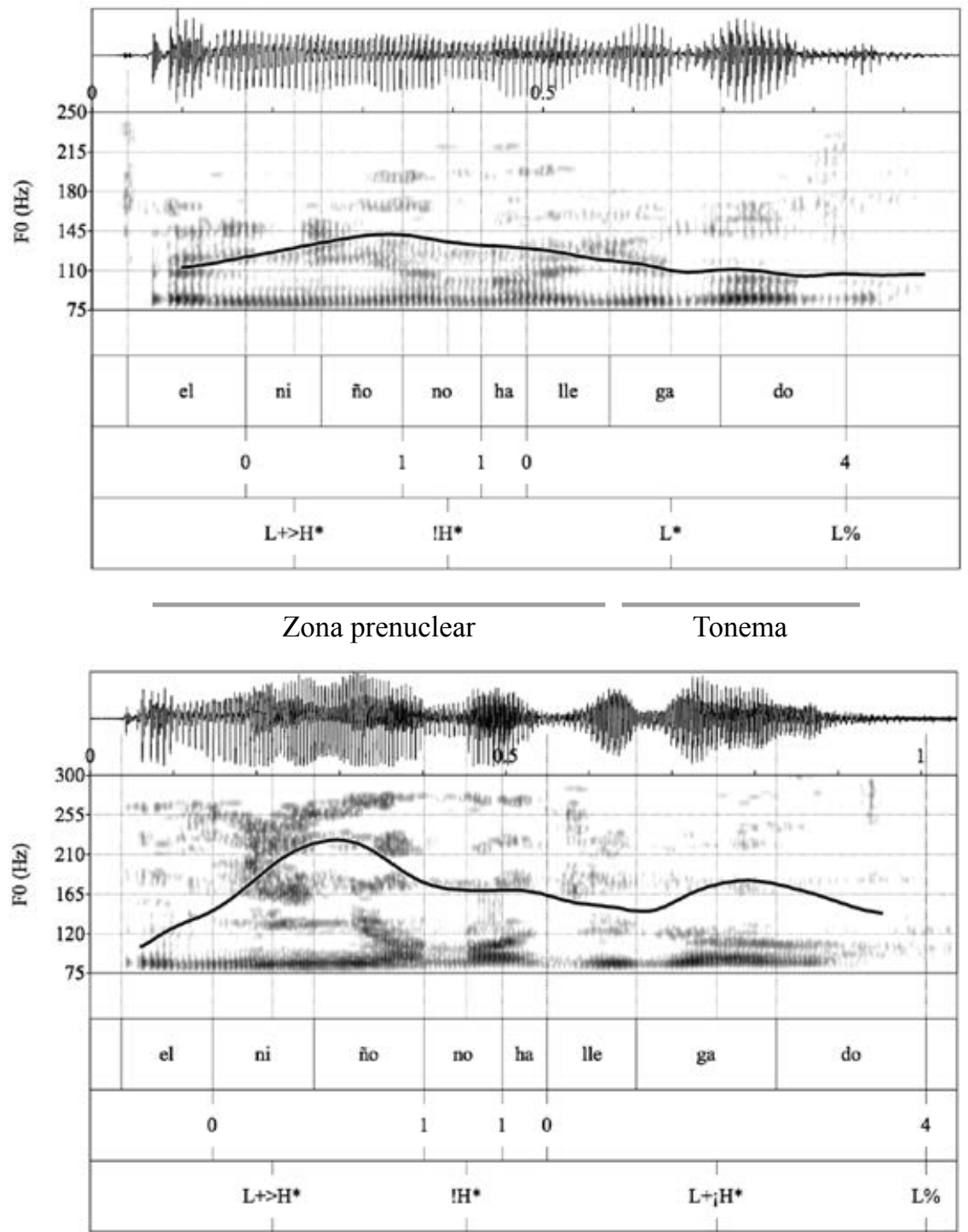
ma circunfleja $\mathrm{L}+{ }_{i} \mathrm{H}^{*} \mathrm{~L} \%$ registrada en el español de la Ciudad de México. La diferencia entre ambas realizaciones se observa en el tonema del enunciado, que se integra por la última sílaba tónica -sílaba nuclear-y la postónica de la emisión. El material fónico previo compone la zona prenuclear, como se señala en (1):

\section{(1) [El niño no ha lle] [gado]} zona prenuclear tonema

El patrón de configuración circunfleja $\mathrm{L}+{ }_{i} \mathrm{H}^{*} \mathrm{~L} \%$, como correlato social, es favorecido por hombres del nivel de instrucción bajo (Martín Butragueño 2011) y puede indizar, además, pertenencia a ciertas redes sociales (Martín Butragueño en prensa). Por lo demás, esta configuración ha sido caracterizada como un rasgo dialectal de la región del Altiplano central ${ }^{6}$, registrada en la capital de Puebla (Willis 2005) y en el habla rural de Tlaxcala (Mendoza 2014). El patrón circunflejo difiere de las realizaciones documentadas en otras regiones de México: en el norte se registran los tonemas $\mathrm{L}+\mathrm{H}^{*} \mathrm{HL} \%$ para la ciudad de La Paz, Baja California Sur (Gil Burgoin 2011), y H* M\% / $\mathrm{L}+\mathrm{H}^{*}$ M\% para Monterrey (Montellano 2017). En el occidente del país -en la ciudad de Guadalajara- se ha registrado la forma ! H* M\% (Orozco 2016). Estas realizaciones contrastan con el tonema no descendente L* H\% (Martín Butragueño 2017) de la zona de la península de Yucatán (ubicada al sur del país, geográficamente en la misma área de Chiapas).

Tomando en cuenta la descripción de la configuración tonal de los enunciados aseverativos de foco amplio en el español de distintas variedades de México, en los siguientes apartados se presentan las configuraciones tonales que distinguen la producción de este tipo enunciativo en el habla de Tuxtla Gutiérrez, Chiapas.

${ }^{6}$ Martín Butragueño (2017) propone una hipótesis geoprosódica basada en los rasgos prosódicos de distintas zonas de México. En el caso de la región del Altiplano central, la entonación circunfleja $\left(\mathrm{L}+{ }_{i} \mathrm{H}^{*} \mathrm{~L} \%\right)$ es el rasgo más prominente que identifica a esta zona del país. 


\section{Metodología}

\section{Informantes e instrumentos de elicitación}

Los datos que se analizan en esta investigación son parte del Corpus Oral del Español de México (Martín Butragueño, Mendoza y Orozco en preparación). La muestra está conformada por 12 hablantes (monolingües) originarios de la ciudad de Tuxtla Gutiérrez y atiende a tres variables preestratificatorias: edad, sexo y nivel de instrucción, según se advierte en la Tabla 1.

\section{TABLA 1}

Distribución de la muestra

\begin{tabular}{lccccccc}
\hline \multirow{2}{*}{ Grupo } & Edad & \multicolumn{2}{c}{ Hombres } & & \multicolumn{2}{c}{ Mujeres } \\
\hline & & \multicolumn{2}{c}{ Nivel de instrucción } & & \multicolumn{2}{c}{ Nivel de instrucción } \\
\cline { 3 - 4 } \cline { 6 - 7 } & & Alto & Bajo & & Alto & Bajo \\
\hline Jóvenes & $20-34$ & 1 & 1 & & 1 & 1 \\
Adultos & $35-54$ & 1 & 1 & & 1 & 1 \\
Mayores & 55 o más & 1 & 1 & & 1 & 1 \\
\hline
\end{tabular}

Los enunciados analizados provienen de distintas fuentes y contemplan distintos grados de control en los datos: $i$ ) espontáneo -conversación de 20 a 30 minutos, aproximadamente-; ii) semiespontáneo ${ }^{8}$-se utilizó una adaptación del cuestionario inductivo de Prieto y Roseano (2009-2013)-; y iii) formal -lectura de enunciados, basado en la metodología del Proyecto AMPER (Atlas Multimedia de la Prosodia del Espacio Románico, Martínez Celdrán y Fernández Planas 2003-2018). En la presente investigación se privilegia el uso de datos en el estilo espontáneo, de tal manera que se analizan 20 enunciados aseverativos

${ }^{7}$ El Corpus Oral del Español de México (COEM) está integrado por datos de doce ciudades de cuatro zonas del país: Norte, Pacífico, Centro y Sur. Entre los objetivos del corpus se ha planteado que a través de la prosodia sea posible ofrecer una imagen actual (2010-2015), desde la perspectiva geográfica y sociolingüística, de las distintas variedades del español de México. Para más información acerca de este proyecto se sugiere visitar la página lef.colmex.mx.

${ }^{8}$ En la metodología del Corpus Oral del Español de México (COEM), las pruebas de mayor grado de control -cuestionario de roles, maptask, lectura de enunciados, etc.- se elicitan sólo con los informantes de nivel de instrucción alto. 
de foco amplio obtenidos en la conversación (menor grado de control) por cada uno de los doce hablantes. Estos datos se complementan con una muestra de 60 enunciados del cuestionario inductivo, provenientes de los informantes de nivel de instrucción alto, en razón de 10 enunciados por 6 hablantes. En total, se analizan 300 enunciados.

Para la selección de la muestra de datos extraída de las entrevistas sociolingüísticas, se consideró la estructura informativa de los enunciados y se descartaron los enunciados con focalización de un constituyente específico o que expresaran contraste -foco estrecho- en el pretonema o en el tonema. Así, se extrajeron los enunciados que en el contexto discursivo correspondieran en su totalidad con información nueva, de modo que todos sus componentes tuvieran el mismo estatus informativo ${ }^{9}$ (Gutiérrez-Bravo 2008).

Como se mencionó líneas arriba, la muestra contempla mayor cantidad de enunciados producidos en estilo espontáneo -con menor grado de control sobre los datos-, pues se busca dar cuenta de los contornos entonativos originados en las situaciones más naturales posibles (cf. Martín Butragueño 2011). No obstante, se reconoce la pertinencia de utilizar instrumentos que permitan tener mayor control sobre los datos, a fin de regular dificultades de carácter técnico -ruido de fondo, traslapes, risas, etc.-, así como factores comunicativos, pragmáticos o intenciones del hablante que puedan dar lugar a modificaciones en los acentos tonales y tonos de juntura de los enunciados analizados. Para obtener enunciados en un contexto con mayor grado de control y establecer la comparación con los patrones entonativos de otras variedades del español, en este trabajo se utiliza, adaptado para México, el cuestionario inductivo basado en la metodología del proyecto ATLES (Prieto y Roseano 20092013). Esta prueba es una tarea de completamiento discursivo que permite obtener distintos tipos enunciativos -en función de un objetivo pragmático- y comparar distintas emisiones entre

${ }^{9}$ Coincido con la anotación de los lectores respecto a la importancia de considerar la función pragmática y la situación comunicativa en el análisis de la variación de los patrones entonativos de los enunciados aseverativos. Como un primer paso para la descripción de los datos de esta variedad que carece de trabajos previos, se ha considerado la estructura informativa de los enunciados, pero el análisis se puede extender a otras variables de tipo pragmático-discursivo para establecer comparaciones con otras variedades del español de México. 
hablantes. En (2) y (3) se ofrecen ejemplos de contextos presentados en esta prueba:

(2) Te preguntan si quieres una pera o una mandarina. Tú respondes que quieres una mandarina. (Respuesta esperada: mandarina / una mandarina).

(3) Vas por la calle y un niño te pregunta por la hora. Contéstale. (Respuesta esperada: Son las doce en punto).

En lo que respecta a las pruebas que implican mayor grado de control sobre los datos, la lectura de enunciados permite obtener pares mínimos entre enunciados aseverativos de foco amplio e interrogativos absolutos. El instrumento de elicitación de lectura de enunciados está diseñado con el fin de tener un control sobre el número de sílabas y la distribución de acentos en la emisión. La prueba incorpora frases sin expansión, frases con expansión en el sujeto, frases con expansión en el objeto $^{10}$. Algunos ejemplos de las frases que integran la prueba de lectura son:

(4) a. La guitarra se toca con obsesión (frase sin expansión en el sujeto/objeto).

$b$. La guitarra clásica se toca con obsesión (frase con expansión en el sujeto).

$c$. La guitarra se toca con paciencia finita (frase con expansión en el objeto).

Ambos instrumentos implican cierto grado de control sobre los datos; en el caso del cuestionario se considera que es posible neutralizar los efectos pragmáticos, partiendo de la idea de que se ofrece un mismo contexto en la elicitación y se obtendría un tipo enunciativo similar. En contraste, la prueba de lectura implica mayor control sobre distintas variables -número de sílabas, posición de los acentos, etc. Con base en el control sobre el efecto pragmático, o en la estructura del enunciado, los datos obtenidos por medio de estos dos instrumentos se consideran en este trabajo como pruebas con mayor grado de control,

${ }^{10}$ Para cada frase se controla la posición del acento, de manera que se obtienen enunciados con palabras oxítonas: saxofón (sujeto), obsesión (objeto); paroxítonas: guitarra (sujeto), paciencia (objeto); proparoxítona: órgano (sujeto), pánico (objeto). 
en oposición a los datos de entrevista (habla espontánea), que conllevan menor grado de control.

La elicitación de datos también incluye un cuestionario sociolingüístico que permite evaluar aspectos sociales, actitudes lingüísticas e integración de los individuos dentro de la comunidad de habla. Este instrumento constituye un elemento adicional para dar cuenta de los distintos factores involucrados en la realización de las configuraciones tonales registradas en esta variedad del español. Así, es posible dar cuenta de la producción de configuraciones tonales con base en una estratificación social y complementar esta información considerando diferencias individuales e interrelación entre los hablantes.

\section{Análisis de los datos}

Los datos se analizan a la luz del modelo métrico-autosegmental $^{11}$ (Pierrehumbert 1980; Sosa 1999; y Ladd 2008); para su transcripción, se utiliza el sistema de notación prosódica $\mathrm{Sp}_{-}$ ToBI (Beckman et al. 2002; Estebas Vilaplana y Prieto 2008; Hualde \& Prieto 2015). La propuesta de acentos tonales y tonos de juntura tiene una base fonética, para la que se ha considerado el umbral de percepción de 1.5 semitonos (Pamies et al. 2001; Murrieta 2016).

El análisis instrumental se llevó a cabo con el programa Praat, versión 6.0.16 (Boersma \& Weenink 2016). Se tomó en cuenta el material prenuclear y nuclear en cada enunciado y se establecieron diferentes parámetros de medición en hercios $(\mathrm{Hz})$ y en semitonos (st). En cuanto a las mediciones, para la configuración global se midió en Hz el techo tonal -el pico más alto del enunciado-y el piso tonal -el punto más bajo del enunciado. También se midió el campo tonal (en st). Para el material prenuclear, se consideró la primera sílaba tónica, el alineamiento del pico tonal y la sílaba postónica. Las mediciones se hicieron en i) el inicio absoluto del enunciado (en $\mathrm{Hz})$ y ii) el valor

11 El modelo métrico-autosegmental surge como una propuesta de la fonología generativa y su propósito abarca dos puntos principales: proponer un sistema de representación fonológica que permita establecer contrastes, con el fin de desarrollar una representación abstracta del sistema entonativo de una lengua, y dar cuenta de las reglas que proyectan las representaciones fonológicas sobre las fonéticas (cf. Pierrehumbert 1980; LAdD 2008; HuAlde 2003). 
del ascenso en el primer pico tonal (st). Para el material nuclear, se midió la frecuencia fundamental (F0 en $\mathrm{Hz}$ ) de $i$ ) el inicio, centro y final de la sílaba tónica; ii) el centro de la pretónica y iii) el inicio, centro y final de la postónica. A partir de estos parámetros se calculó (en st) la diferencia entre $i$ ) el inicio y centro de la tónica; ii) centro y final de la tónica y iii) centro/final de la tónica respecto al centro/final de la postónica.

Para la transcripción de datos, como acabo de referir, se siguen las convenciones del sistema de notación prosódica $\mathrm{Sp}_{-}$ ToBI. De este modo, se representa la estructura prosódica del enunciado con el uso de diferentes niveles de transcripción: $i$ ) ortográfico, con la segmentación por sílabas; ii) de separación prosódica o cesuras, con valores en una escala de 0 a 4 que dan cuenta del nivel en la jerarquía prosódica (Nespor y Vogel 1994) -el valor 0 indica ausencia de cesura en grupos acentuales; 1 señala el linde entre palabras fonológicas; 2 distingue el nivel de frase fonológica; 3 marca frase entonativa menor; y 4 indica frase mayor o enunciado fonológico. Finalmente, en el nivel iii) se marcan los acentos tonales (anclados a sílabas tónicas) y tonos de juntura (asociados con lindes de frases).

En los siguientes apartados se ofrece el repertorio de acentos tonales y tonos de juntura y se presentan las configuraciones nucleares y prenucleares registradas en los datos de Tuxtla Gutiérrez. Se observarán los rasgos prosódicos que distinguen esta variedad frente a los datos de la Ciudad de México y de Mérida, Yucatán. También se exponen los factores sociales que influyen en la realización de una determinada configuración tonal.

\section{Resultados}

Repertorio de acentos tonales y tonos de juntura

El repertorio de acentos tonales y tonos de juntura ha sido adaptado de la propuesta de Estebas Vilaplana y Prieto (2008) y Hualde y Prieto (2015). En los enunciados aseverativos de la variedad de Tuxtla Gutiérrez, se registran dos acentos nucleares monotonales: $\mathrm{H}^{*}$ y $\mathrm{L}^{*}$, aunque este último muestra una escasa aparición, específicamente en los datos del hombre del grupo de edad concerniente a adultos y al de nivel de instrucción alto. En posición nuclear, la realización $\mathrm{L}^{*}$ se ha documentado 
tanto en la variedad de la Ciudad de México (De-la-Mota $e t$ al. 2010), como en los datos de Mérida, Yucatán (Mendoza et al. 2016). Además, el acento $H^{*}$ y la variante ! $H^{*}$ se han documentado en posición nuclear y prenuclear en los datos de Mérida, de modo semejante a la variedad de Tuxtla Gutiérrez ${ }^{12}$.

TABLA 2

Acentos monotonales

\begin{tabular}{|c|c|c|}
\hline Esquema & Transcripción & Descripción \\
\hline & $\mathrm{L}^{*}$ & $\begin{array}{l}\text { Este acento se caracteriza por } \\
\text { un valor bajo del F0 derivado } \\
\text { de un descenso progresivo o del } \\
\text { sostenimiento de un valor bajo } \\
\text { de F0 de la sílaba pretónica. Se } \\
\text { produce en el rango mínimo del } \\
\text { hablante. Se registra en posición } \\
\text { nuclear. }\end{array}$ \\
\hline & $\mathrm{H}^{*}$ & $\begin{array}{l}\mathrm{El} \text { acento tonal } \mathrm{H}^{*} \text { se caracteriza } \\
\text { por la producción del F0 en un } \\
\text { rango elevado. También se rea- } \\
\text { liza con la forma } \mathrm{H}^{*} \text {, es decir, } \\
\text { con un ascenso menor a } \mathrm{H}^{*} \text {. Se } \\
\text { registra en posición nuclear y } \\
\text { prenuclear. }\end{array}$ \\
\hline
\end{tabular}

En posición prenuclear, se registran los acentos nucleares bitonales $\mathrm{L}+>\mathrm{H}^{*}$ y $\mathrm{L}^{*}+\mathrm{H}$, ambos con el pico tonal alineado en la sílaba postónica. Como se mencionó en el apartado de antecedentes (cf. supra), este alineamiento corresponde con el descrito para la curva melódica de los enunciados aseverativos de foco amplio en distintas variedades del español -incluida la de la Ciudad de México. En los datos de Tuxtla, el desplazamiento del pico tonal en posición prenuclear se observa con menor recurrencia en comparación con la realización que presenta alineamiento en la sílaba tónica. En el apartado dedicado a la descripción del primer pico tonal del enunciado, se discutirá la influencia de los factores sociales en la distribución de los acentos tonales en posición prenuclear.

12 La realización del acento tonal $\mathrm{H}^{*} \mathrm{y} ! \mathrm{H}^{*}$ en posición nuclear y prenuclear también se ha documentado en los enunciados aseverativos de foco amplio en el español rural del centro de México (Mendoza 2014). 
Cabe señalar que tanto en la propuesta de Beckman et al. (2002), como en la de Hualde y Prieto (2015), se ha empleado la notación $\mathrm{L}+<\mathrm{H}^{*}$ para la transcripción del acento tonal con alineamiento en la sílaba postónica. En este trabajo se seguirá la propuesta de Estebas Vilaplana y Prieto (2008) para la transcripción del acento tonal con pico diferido (o desplazado) con la notación $\mathrm{L}+>\mathrm{H}^{*}$ (delayed peak). Para la descripción de los datos de Tuxtla, se considera que el uso de esta notación permitirá distinguir el desplazamiento en posición prenuclear, frente a la realización documentada con el pico tonal alineado antes del linde de la sílaba tónica, etiquetado como $\mathrm{L}+<\mathrm{H}^{*}$, según se observa en la Tabla 3.

Uno de los rasgos más llamativos en los datos de Tuxtla Gutiérrez es la realización del acento tonal $\mathrm{L}+\mathrm{H}^{*}$-con alineamiento del pico tonal dentro de la sílaba tónica- en posición prenuclear (también llamado alineamiento temprano o prealineamiento). Para los datos del español de México, éste se ha documentado en variedades en situación de contacto (véase Orozco 2017) para español-chichimeco, y Olivar (en preparación) para español-náhuatl. En las variedades del centro, este tipo de alineamiento se ha asociado con factores de expresividad (Martín Butragueño 2016) y sociolingüísticos -en redes de inmigrantes (Martín Butragueño en prensa) e indización de pertenencia local a una comunidad (Mendoza 2014). También se registra en los datos del español yucateco (Michnowicz \& Barnes 2013; Mendoza et al. 2016), sin que se haya encontrado influencia evidente del bilingüismo como factor que favorezca el alineamiento temprano ${ }^{13}$.

13 El alineamiento temprano se ha descrito en otras variedades del español; a saber, en República Dominicana (Willis 2010), Puerto Rico (Armstrong 2010) y Colombia (Velásquez 2013). Se ha mencionado que este tipo de alineamiento puede ser un rasgo de las variedades de español en contacto (italiano, quechua y vasco; Colantoni 2011, p. 22). En este mismo contexto, en Perú se ha documentado en situación de contacto español-quechua (O'Rourke 2005) y en Guatemala para contacto españolK'ichee' (BAIRD 2015). Por lo demás, LiPski (2011, p. 85) menciona que el prealineamiento del pico tonal marca diferencias dialectales y que es un patrón sociolingüísticamente marcado, asociado de manera errónea "with Spanish-recessive bilingual speakers, even though some monolingual Spanish speakers exhibit the same type of pitch accent”. El autor hace referencia a casos de comunidades afro-hispánicas en Latinoamérica -en regiones de Bolivia y casos de palenquero en Colombia- y además menciona la ausencia de descenso final (downdrift) en estas variedades. Asimismo, documenta 
TABLA 3

Acentos bitonales

\begin{tabular}{|c|c|c|}
\hline Esquema & Transcripción & Descripción \\
\hline & $\mathrm{L}+>\mathrm{H}^{*}$ & $\begin{array}{l}\text { Este acento tonal se caracteriza } \\
\text { por un ascenso progresivo del F0 } \\
\text { a lo largo de la sílaba tónica que } \\
\text { se desplaza y culmina en la pos- } \\
\text { tónica (delayed peak). Se registra } \\
\text { en posición prenuclear. }\end{array}$ \\
\hline$/$ & $\mathrm{L}^{*}+\mathrm{H}$ & $\begin{array}{l}\text { El acento tonal } \mathrm{L}^{*}+\mathrm{H} \text { se realiza } \\
\text { como un tono } \mathrm{L}^{*} \text { en la sílaba } \\
\text { tónica con un ascenso del } \mathrm{F} 0 \\
\text { en la sílaba postónica (late rising } \\
\text { accent). Se registra en posición } \\
\text { prenuclear. }\end{array}$ \\
\hline
\end{tabular}

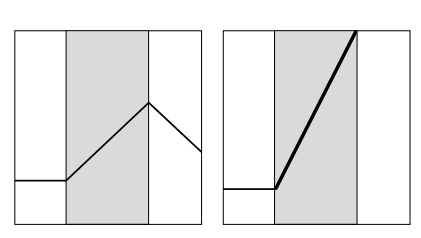

El acento tonal $\mathrm{L}+\mathrm{H}^{*}$ se realiza como una elevación desde el inicio de la sílaba tónica con alineamiento del pico tonal al $\mathrm{L}+{ }_{j} \mathrm{H}^{*}$ final de ésta (early rising accent). Se registra en posición nuclear y prenuclear. La variante $\mathrm{L}+i \mathrm{H}^{*}$ se realiza con un ascenso mayor a 3 semitonos (fig. derecha).

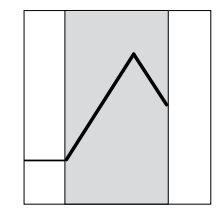

$\mathrm{El}$ acento tonal $\mathrm{L}+<\mathrm{H}^{*}$ se realiza con el pico tonal alineado en la parte media o antes del final de $\mathrm{L}+<\mathrm{H}^{*}$ la sílaba tónica (very early peak). Se registra en posición nuclear y prenuclear. El valor del ascenso puede superar los 3 semitonos.

Por lo demás, los tonos de juntura final y de frase intermedia muestran las mismas formas monotonales y bitonales. Para el caso de los enunciados analizados, el tono de juntura bitonal se registra con poca frecuencia, y predomina el descenso final. Los casos de tono de juntura bitonal -o complejos- pueden relacionarse con el alargamiento de la sílaba postónica. Para la descripción de los datos de Tuxtla, se han integrado las propuestas de

casos de entonación "norteña" (Ciudad de Chihuahua, en el norte de México, y Nuevo México) con secuencias de acentos tonales $\mathrm{L}+\mathrm{H}^{*}$ en la parte pretonemática del enunciado. 
Hualde y Prieto (2015) y Estebas Vilaplana y Prieto (2008) con los tonos de juntura ! $\%$ y $\mathrm{M} \%$, que, en el primer caso, puede dar cuenta del sostenimiento del tono, a partir de un rango alto anterior, o de un ascenso menor a $1.5 \mathrm{st}$. El tono M\% permite expresar un movimiento descendente menor a $1.5 \mathrm{st}$, que se distingue del descenso $\mathrm{L} \%$. En ambos casos, se trata de la realización de un tono medio - con un sostenimiento o un modesto movimiento tonal. En este primer acercamiento a los datos,

TABLA 4

Tonos de juntura monotonales

\begin{tabular}{|c|c|c|}
\hline Tonos & Transcripción & Descripción \\
\hline & $\mathrm{L} \%$ & $\begin{array}{l}\text { Se realiza como un descenso } \\
\text { progresivo -igual o mayor a } 1.5 \\
\text { st- derivado de un F0 alto en la } \\
\text { sílaba nuclear (izquierda) o como } \\
\text { un tono bajo sostenido a partir de } \\
\text { un F0 bajo anterior (derecha). }\end{array}$ \\
\hline & $! \mathrm{H} \%$ & $\begin{array}{l}\text { Tono con ascenso menor a } 1.5 \mathrm{st} \\
\text { derivado de un tono bajo ante- } \\
\text { rior (izquierda). También se rea- } \\
\text { liza como un tono sostenido a } \\
\text { partir de un F0 alto anterior. }\end{array}$ \\
\hline & M\% & $\begin{array}{l}\text { Se realiza como un leve descenso } \\
\text { a partir de un F0 alto anterior. El } \\
\text { valor del movimiento es menor } \\
\text { a } 1.5 \mathrm{st} \text {. }\end{array}$ \\
\hline
\end{tabular}

TABLA 5

Tonos de junturas bitonales
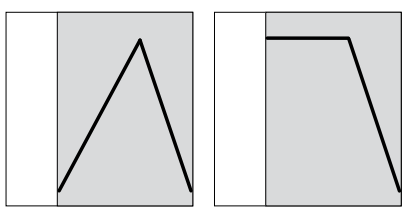

Movimiento de ascenso-descenso de F0 después de un acento nuclear bajo (izquierda). Otra HL\% realización es con el sostenimiento del $\mathrm{F} 0$ en un rango alto, seguido de un descenso posterior (derecha). 
la transcripción corresponde a un nivel fonético; por lo tanto, se considera pertinente hacer la distinción entre un tono sostenido, o ascenso poco prominente (!H\%), y un descenso poco pronunciado (M\%). La comparación con otros tipos enunciativos y objetivos pragmáticos en futuras investigaciones permitirá apoyar la formalización de un solo tono de juntura.

\section{Configuraciones nucleares}

En los datos de enunciados aseverativos de foco amplio en la variedad de Tuxtla Gutiérrez, se han registrado distintas configuraciones nucleares que alternan entre la forma con un acento nuclear bitonal $\mathrm{L}+(i) \mathrm{H}^{*} \mathrm{~L} \% / ! \mathrm{H} \%$ y el monotonal ! $\mathrm{H}^{*} \mathrm{~L} \%$, en ambos casos con junturas descendentes. El acento nuclear bitonal se documenta con mayor frecuencia (véase infra Tabla 6), en un $70 \%(\mathrm{~F}=210)$, mientras que el acento nuclear monotonal se observó en un $30 \%(\mathrm{~F}=90)$.

La forma $\mathrm{L}+\mathrm{H}^{*} \mathrm{~L} \%$ se realiza como un acento con inicio bajo y ascenso progresivo a lo largo de la sílaba tónica, y el pico tonal alineado al final de ésta. El uso del diacrítico de upstep (i) para la variante $\mathrm{L}+{ }_{i} \mathrm{H}^{*}$ indica que el valor del movimiento ascendente es superior a 3 semitonos (cf. Martín Butragueño 2011). Se ha observado que el pico tonal en el acento $\mathrm{L}+\mathrm{H}^{*}$ puede alinearse antes del linde de la sílaba tónica, o incluso en el centro de ésta. El rasgo de alineamiento temprano del pico nuclear en estos datos es similar al documentado en los datos de español yucateco (Mendoza et al. 2016). En el caso de los datos de Tuxtla, el acento nuclear bitonal se ha registrado con mayor recurrencia en los datos con menor grado de control -habla espontánea-y, en menor medida, en los datos extraídos de las pruebas con mayor grado de control. La Figura 2 muestra un ejemplo de la configuración nuclear $\mathrm{L}+\mathrm{iH}^{*} \mathrm{~L} \%$.

El enunciado de la Figura 2 fue proferido en estilo de habla espontáneo (con menor grado de control en los datos). Se observa el tonema con el acento nuclear bitonal $\mathrm{L}+\mathrm{j}_{\mathrm{H}} \mathrm{H}^{*}$ con un ascenso de 6 semitonos, seguido de un tono de juntura L\%. Es preciso mencionar que el movimiento de ascenso en el acento nuclear puede alcanzar los 7 semitonos. La forma nuclear bitonal y el prominente movimiento en el tonema se distinguen de la forma descendente que se ha descrito para otras variedades del español (cf. Hualde \& Prieto 2015). También difieren de la 
FigurA 2

Oscilograma, espectrograma y curva melódica del enunciado

Nosotros somos los obreros, producido por un hombre, grupo de edad correspondiente a jóvenes, nivel de instrucción bajo

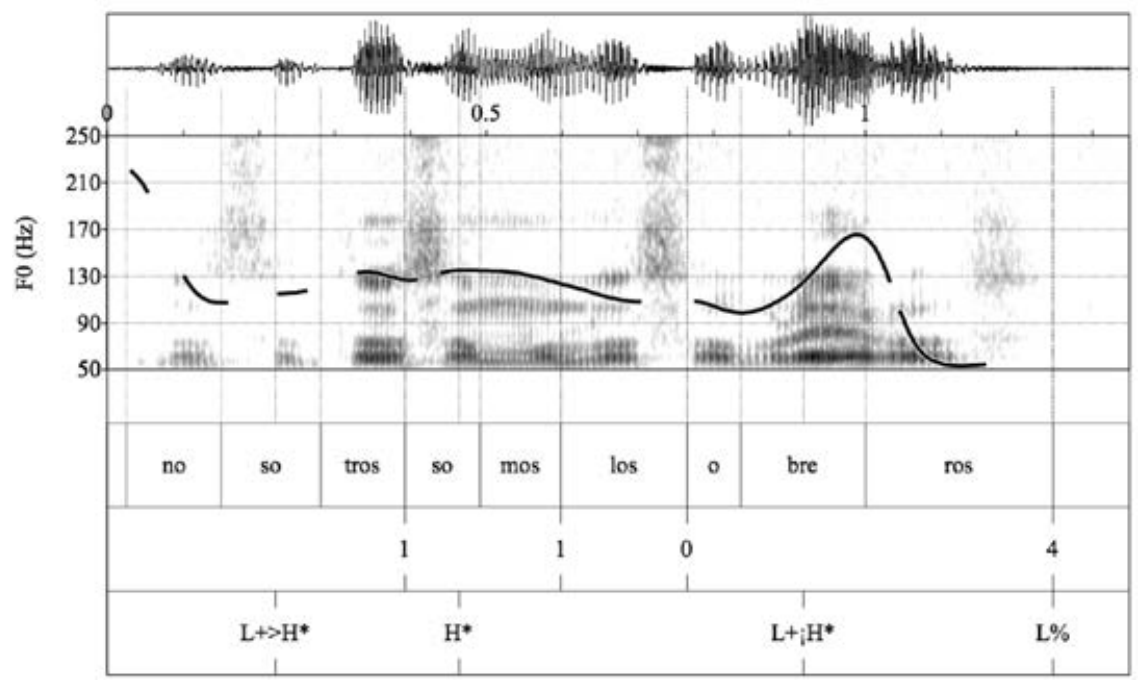

forma $\mathrm{L}^{*} \mathrm{~L} \%$, registrada en los datos de la Ciudad de México (De-la-Mota et al. 2010).

Además, se registra una configuración nuclear $\mathrm{L}+{ }_{i} \mathrm{H}^{*} \mathrm{HL} \%$ con una juntura compleja. El descenso final es similar al de la forma L\%, pero el pico tonal del acento nuclear continúa su trayectoria ascendente en la primera parte de la sílaba postónica, como se puede apreciar en la Figura 3.

El enunciado de la Figura 3 muestra la configuración $\mathrm{L}+{ }_{i} \mathrm{H}^{*}$ HL\% con un ascenso de 7.4 st en el acento nuclear. La emisión realizada por un hombre mayor muestra un acento nuclear similar al de la Figura 2, producido por un hombre joven. Así, una de las primeras pistas que se han identificado en esta variedad del español es la distribución de los movimientos tonales más prominentes en el enunciado, que en el caso de la Figura 2 se presenta en el tonema del enunciado. Aunque en la Figura 3 la mayor prominencia se percibe en el primer pico tonal -con un incremento de 11 st-, el ascenso de 7.4 st en el tonema es semejante al de la emisión del hombre joven.

El acento nuclear bitonal $\mathrm{L}+(i) \mathrm{H}^{*}$ es el más documentado en la muestra de datos analizada (cf. infra Tabla 6). Es importan- 
FIgURA 3

Oscilograma, espectrograma y curva melódica del enunciado

Se armó un gran problema, producido por un hombre, grupo de edad correspondiente a mayores, nivel de instrucción alto

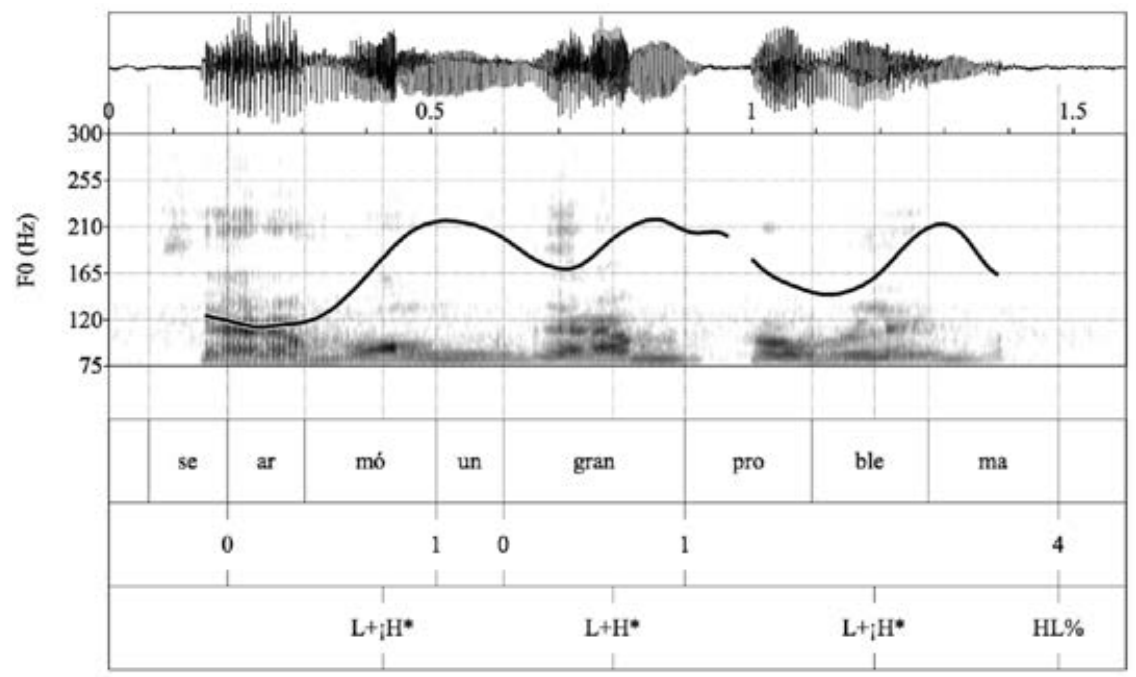

te mencionar que el valor del ascenso puede disminuir en los datos de los hablantes más jóvenes, que incluso muestran una tendencia a la realización de formas monotonales -en pruebas con mayor grado de control. La Figura 4 presenta la realización del acento nuclear $\mathrm{L}+{ }_{i} \mathrm{H}^{*}$ producido por una mujer joven en la prueba del cuestionario inductivo.

$\mathrm{Al}$ observar las configuraciones nucleares de los tres enunciados, se observa una similitud en la forma del acento nuclear bitonal $\mathrm{L}+{ }_{i} \mathrm{H}^{*}$, pero con diferencias en el valor del ascenso -con $4.3 \mathrm{st}$ en la emisión de la mujer joven, en contraste con el ascenso superior a 6 st en la emisión de los hombres. La juntura final también registra diferencias en su ejecución, con una forma descendente en las emisiones de los hombres, en contraste con el sostenimiento del tono !H\% en la enunciación de la mujer joven. Se advierte otra diferencia en la configuración prenuclear, con secuencias de acentos monotonales en la emisión de la mujer (la discusión acerca del material prenuclear se profundizará en el siguiente apartado).

Tomando en cuenta la configuración global del enunciado, se observa que tanto en la curva melódica de la Figura 3, como de la 4, se conserva la realización del descenso a partir de la cul- 
FIGURA 4

Oscilograma, espectrograma y curva melódica del enunciado

Son las doce del día, producido por una mujer, grupo de edad correspondiente a jóvenes, nivel de instrucción alto

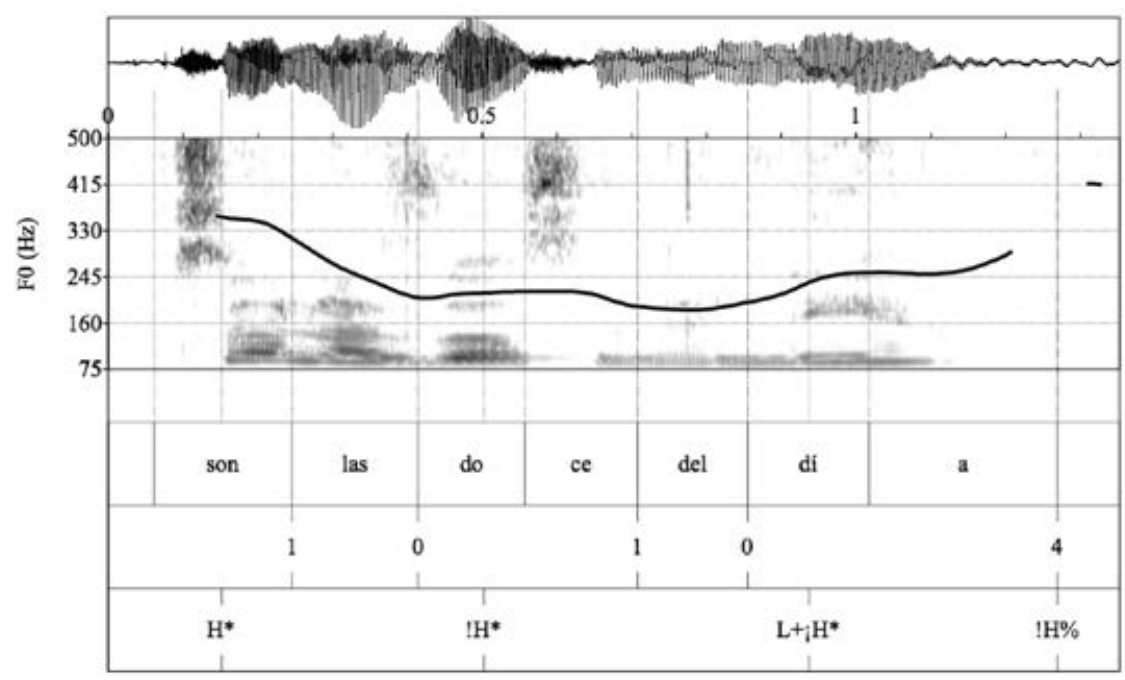

minación del primer pico tonal (el techo tonal en ambas emisiones). En este sentido, una primera propuesta apunta a que la forma del acento nuclear bitonal y el prominente descenso a partir del primer pico tonal son rasgos que podrían distinguir a esta variedad del español.

Respecto al movimiento ascendente en el tonema, se ha notado la influencia que ejerce sobre éste el grado de control de los datos, según el tipo de prueba. Por consecuencia, en los tres grupos de edad se observó que el valor del movimiento se puede moderar o neutralizar en los enunciados proferidos en la elicitación del cuestionario inductivo y en la prueba de lectura. Es decir, se conserva la forma bitonal del acento nuclear $\mathrm{L}+\mathrm{H}^{*}$, pero el movimiento ascendente es más moderado. Así, se puede sugerir que una tarea con mayor grado de control en los datos motivará que las inflexiones muestren valores menos elevados, en contraste con los datos de entrevista. Obsérvese el enunciado de la Figura 5, obtenido en la elicitación del cuestionario inductivo.

En este enunciado, el acento nuclear $\mathrm{L}+\mathrm{H}^{*}$ muestra un ligero movimiento ascendente, con valor de $1.5 \mathrm{st}$, que contrasta con los movimientos prominentes de hasta 7 st registrados en 
FigurA 5

Oscilograma, espectrograma y curva melódica del enunciado

Mario está tocando el órgano, producido por una mujer, grupo de edad correspondiente a mayores, nivel de instrucción alto

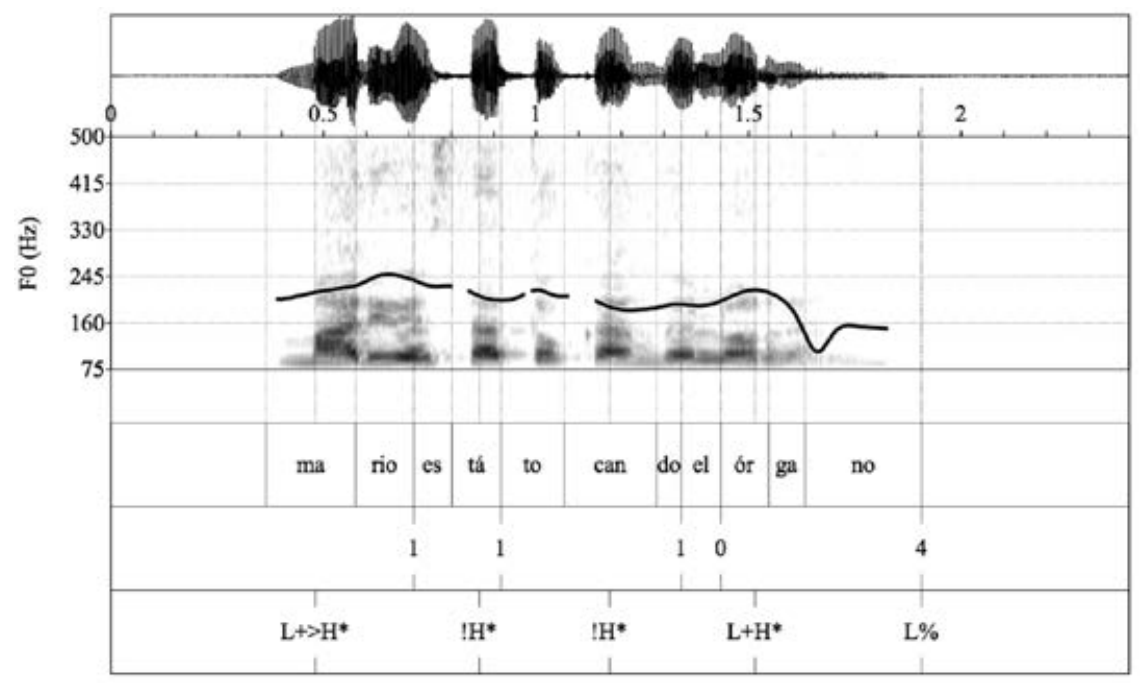

datos de habla espontánea. Otra diferencia se nota en el pretonema con la realización del acento tonal con pico desplazado hacia la postónica $\mathrm{L}+>\mathrm{H}^{*}$ (véase el siguiente apartado para la discusión acerca de este acento). En la configuración global, se observa que el descenso entre el punto más alto del enunciado y el tonema es menos pronunciado en comparación con las emisiones de habla espontánea.

A propósito de la configuración con acento nuclear monotonal ! $\mathrm{H}^{*} \mathrm{~L} \%$, la curva melódica no revela inflexiones prominentes en la sílaba nuclear y tiende a descender en la sílaba postónica. En la Figura 6 se muestra la realización de la configuración nuclear ! $\mathrm{H}^{*} \mathrm{~L} \%$, donde el descenso del F0 en el acento nuclear es de 0.9 st -menor al umbral de 1.5 st para ser considerado una forma bitonal. Si comparamos las distintas realizaciones, el elemento local que distingue a las tres emisiones es el acento nuclear, con ascensos prominentes en las emisiones con la forma $\mathrm{L}+{ }_{i} \mathrm{H}^{*}$, en contraste con la ausencia de movimiento en la forma monotonal ! $\mathrm{H}^{*}$.

Si bien el acento nuclear ! $\mathrm{H}^{*}$, seguido de un descenso L\%, se registra con menor frecuencia (véase Tabla 6), su proyección 
Figura 6

Oscilograma, espectrograma y curva melódica del enunciado

Son las cinco y media, producido por una mujer, grupo de edad correspondiente a mayores, nivel de instrucción alto

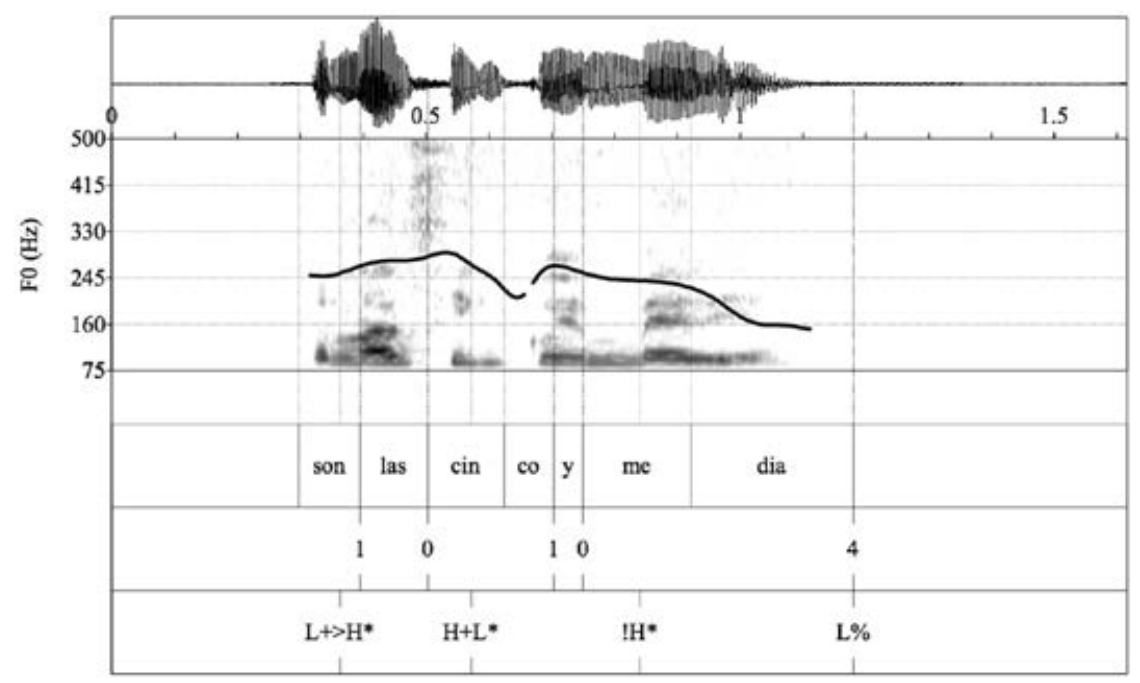

TABLA 6

Acentos nucleares $(N=300)$

\begin{tabular}{lcc}
\hline Acento nuclear & Frecuencia $(F)$ & Porcentaje $(\%)$ \\
\hline Bitonal & 210 & $70 \%$ \\
Monotonal & 90 & $30 \%$ \\
Total & 300 & $100 \%$ \\
\hline
\end{tabular}

social y estilística adquiere relevancia. Al tratarse de la configuración más parecida a la registrada en la variedad del centro de México (véase L* L\% supra, en la Figura 1), su producción se puede vincular con la neutralización de los recursos prosódicos que distinguirían a la variedad de Tuxtla -con los ascensos prominentes en el acento nuclear- a favor de formas monotonales o de ascensos moderados.

En tablas se ofrece la información acerca de la distribución de acentos nucleares en los enunciados aseverativos de la variedad de Tuxtla. Los datos de la Tabla 6 dan cuenta de la mayor frecuencia de acentos nucleares bitonales (210 casos en 
la muestra de 300 enunciados), mientras que en la Tabla 7 se registra la frecuencia de acentos bitonales con ascenso superior a 3 st.

\section{TABLA 7}

Ascenso en acento nuclear bitonal $(N=210)$

\begin{tabular}{lcc}
\hline Valor de ascenso & Frecuencia $(F)$ & Porcentaje $(\%)$ \\
\hline Mayor a 3 st & 113 & $54 \%$ \\
Menor a 3 st & 97 & $46 \%$ \\
Total & 210 & $100 \%$ \\
\hline
\end{tabular}

En una primera aproximación a los datos, se distinguieron los porcentajes de la frecuencia de los distintos ascensos por grupos de edad (Tabla 8) y se notó que los ascensos con valor superior a 3 semitonos se registran con mayor recurrencia en los datos obtenidos del grupo de adultos y mayores, y disminuyen en las emisiones de los jóvenes.

\section{TABLA 8}

Valor del ascenso en acento nuclear bitonal y grupo de edad $(N=210)$

\begin{tabular}{lcc}
\hline Grupo & Mayor a 3 st $(F y \%)$ & Menor a 3 st $(F y \%)$ \\
\hline Jóvenes & $28(43.8 \%)$ & $36(56.2 \%)$ \\
Adultos & $42(61.8 \%)$ & $26(38.2 \%)$ \\
Mayores & $43(55.1 \%)$ & $35(44.9 \%)$ \\
Total & 113 & 97 \\
\hline
\end{tabular}

Para dar cuenta de la distribución social de la forma nuclear bitonal, se elaboró un análisis estadístico con Goldvarb (Sankoff et al. 2012), atendiendo a las variables: $i$ ) género; ii) grupo de edad; iii) nivel de instrucción y iv) tipo de prueba -mayor o menor grado de control en los datos. El análisis binomial de ascenso y descenso (Tabla 9) seleccionó como significativo el factor género y tipo de prueba. Los resultados mostraron que el acento nuclear bitonal es favorecido por los hombres (0.581) y el menor grado de control en las pruebas (0.538), es decir, en las entrevistas sociolingüísticas. 
TABLA 9

Acentos nucleares bitonales

\begin{tabular}{cc}
\hline Género & Prueba (mayor o menor control) \\
\hline Hombres: 0.581 & 1 (mayor grado de control): 0.353 \\
Mujeres: 0.419 & 2 (menor grado de control): 0.538 \\
\hline
\end{tabular}

Log. Verosimilitud $=-176.969 ;$ Significatividad $=0.014$.

La forma bitonal difiere de la terminación descendente $\mathrm{L}^{*} \mathrm{~L} \%$ registrada en los datos de la Ciudad de México (De-laMota et al. 2010), pero es similar al patrón circunflejo $\mathrm{L}+\mathrm{iH}^{*}$ $\mathrm{L} \%$, documentado para esta variedad del español mexicano central (Martín Butragueño 2004, 2011). Asimismo, la configuración nuclear $\mathrm{L}+{ }_{i} \mathrm{H}^{*} \mathrm{~L} \%$ de Tuxtla muestra una diferencia respecto al tonema con juntura ascendente $\mathrm{L}^{*} \mathrm{H} \%$ (Martín Butragueño 2017) y la configuración ! $\mathrm{H}^{*} \mathrm{M} \%$, registrada en la variedad de Mérida, Yucatán (Mendoza et al. 2016). La configuración nuclear es diferente en las dos variedades del sur -Tuxtla y Mérida-, pero de alguna manera se podría observar una forma semejante; es decir, una secuencia (LH) en ambos casos. La diferencia es que en la variedad de Mérida, el acento nuclear tiene un tono bajo $\mathrm{L}^{*}$ y el ascenso se produce en la juntura; mientras que en la variedad de Tuxtla, la forma ascendente se registra desde el acento nuclear $\mathrm{L}+\mathrm{H}^{*}$, seguido de un descenso, que permite distinguir esta variedad frente a la yucateca.

En esta sección hemos visto que las configuraciones con acento nuclear bitonal se ven favorecidas por los hombres y por el menor grado de control de las pruebas. Una de las cuestiones que se tratarán en el siguiente apartado es la interacción entre la configuración nuclear y prenuclear con el fin de dar cuenta de los rasgos que distinguen a los enunciados aseverativos en la variedad de Tuxtla Gutiérrez.

\section{Acentos prenucleares: primer pico tonal del enunciado}

El repertorio de acentos tonales en posición prenuclear incluye la forma bitonal con alineamiento en la sílaba tónica $\mathrm{L}+\mathrm{H}^{*}$ y la variante $\mathrm{L}+i \mathrm{H}^{*}$-con ascenso superior a 3 st. Igualmente, se registra el acento monotonal $\mathrm{H}^{*}$ con la variante $! \mathrm{H}^{*}$. Estas variantes son las más recurrentes en los datos analizados y tie- 
nen en común que el pico tonal culmina en la sílaba tónica -también llamado prealineamiento o alineamiento temprano. Este alineamiento del primer pico tonal se ha documentado asimismo en la variedad de Mérida, Yucatán (Michnowicz \& Barnes 2013; Mendoza et al. 2016) y se distingue de la forma con pico tonal desplazado $\mathrm{L}+>\mathrm{H}^{*}$; registrada en el español mexicano central (De-la-Mota et al. 2010; Martín Butragueño 2014b) y en otras variedades del español (Prieto \& Roseano 2010; Hualde \& Prieto 2015). El esquema ${ }^{14}$ de la Figura 7 indica el alineamiento del pico tonal en posición prenuclear documentado en los enunciados aseverativos de la variedad de Tuxtla Gutiérrez y en el español de la Ciudad de México (español mexicano central o EMC).

FigurA 7

Comparación de alineamientos de picos tonales en posición prenuclear

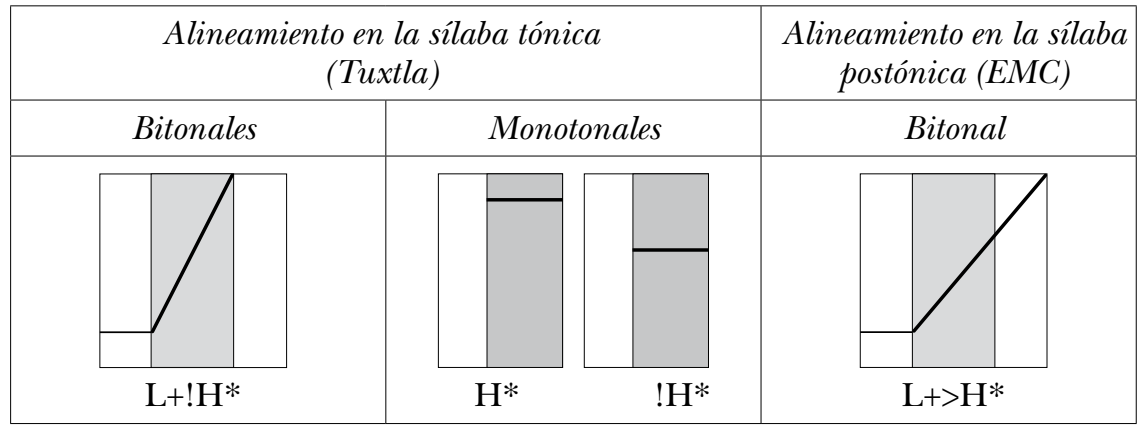

El esquema anterior muestra la diferencia en el alineamiento del primer pico tonal. Para el caso de Tuxtla, se observa la culminación del pico tonal en el linde derecho de la sílaba tónica (alineamiento temprano); en contraste, para la variedad de la Ciudad de México, se distingue un movimiento de ascenso progresivo en la sílaba tónica, que se prolonga hacia la postónica (pico desplazado o diferido). Cabe mencionar que la realización de las formas con alineamiento temprano no es un hecho categórico en los datos de Tuxtla, sino que también se registra el acento tonal con pico desplazado $\mathrm{L}+>\mathrm{H}^{*}$, aunque en menor

14 Representaciones esquemáticas basadas en la propuesta de EstEBAs Vilaplana y Prieto 2008. En la imagen, la casilla sombreada indica la sílaba tónica. 
proporción. La Tabla 10 ofrece la frecuencia y porcentaje de los acentos tonales alineados en la sílaba tónica y postónica en posición prenuclear.

TABLA 10

Alineamiento en acento prenuclear. Primer pico tonal $(N=300)$

\begin{tabular}{lcc}
\hline \multicolumn{1}{c}{ Alineamiento } & Frecuencia $(F)$ & Porcentaje $(\%)$ \\
\hline Sílaba tónica & 242 & $80.7 \%$ \\
Sílaba postónica & 58 & $19.3 \%$ \\
Total & 300 & $100 \%$ \\
\hline
\end{tabular}

Los datos de la Tabla 10 exponen la mayor recurrencia de acentos tonales alineados en la sílaba tónica, es decir que el alineamiento temprano se documenta en un $80.7 \%$, mientras que la realización con alineamiento en la sílaba postónica sólo se registra en un $19.3 \%$ de los casos. Estos resultados indican que el prealineamiento no se produce de manera categórica.

El enunciado de la Figura 8, obtenido en un contexto de habla espontánea, es ejemplo de la producción de una secuencia de acentos tonales $\mathrm{L}+\mathrm{H}^{*} \mathrm{y} ! \mathrm{H}^{*}$ en el material prenuclear del enunciado. El primer acento tonal tiene un ascenso de 8 st, y a partir de la culminación del pico tonal -el techo tonal del enunciado- ocurre un prominente descenso en el cuerpo del enunciado, que abarca hasta el linde derecho de la sílaba prenuclear. En contraste, la realización del acento monotonal $\mathrm{H}^{*}$ sin inflexiones en la sílaba tónica se muestra en la emisión de la Figura 9, extraída del cuestionario inductivo. En este enunciado, el inicio alto $\mathrm{H}^{*}$ constituye el techo tonal del enunciado. A partir de la primera sílaba tónica, se observa un descenso en el cuerpo del enunciado, que abarca hasta la sílaba prenuclear del tonema. En la sílaba nuclear se produce un moderado ascenso -de 2 stetiquetado como $\mathrm{L}+\mathrm{H}^{*}$, seguido de una juntura $! \mathrm{H} \%$, es decir, un tono sostenido a partir del F0 alto anterior.

Una comparación entre las dos emisiones muestra similitudes en la configuración global, es decir, se observa una declinación que ocurre a partir de la culminación del primer pico tonal -el más alto de la emisión en ambos enunciados (similar a lo que se observa en los datos del apartado de configuraciones nucleares; cf. supra). Esta declinación corresponde al escalonamiento descrito para los enunciados aseverativos en español. 
FigurA 8

Oscilograma, espectrograma y curva melódica del enunciado

La escuela estaba bonita, producido por un hombre, grupo de edad correspondiente a adultos, nivel de instrucción alto

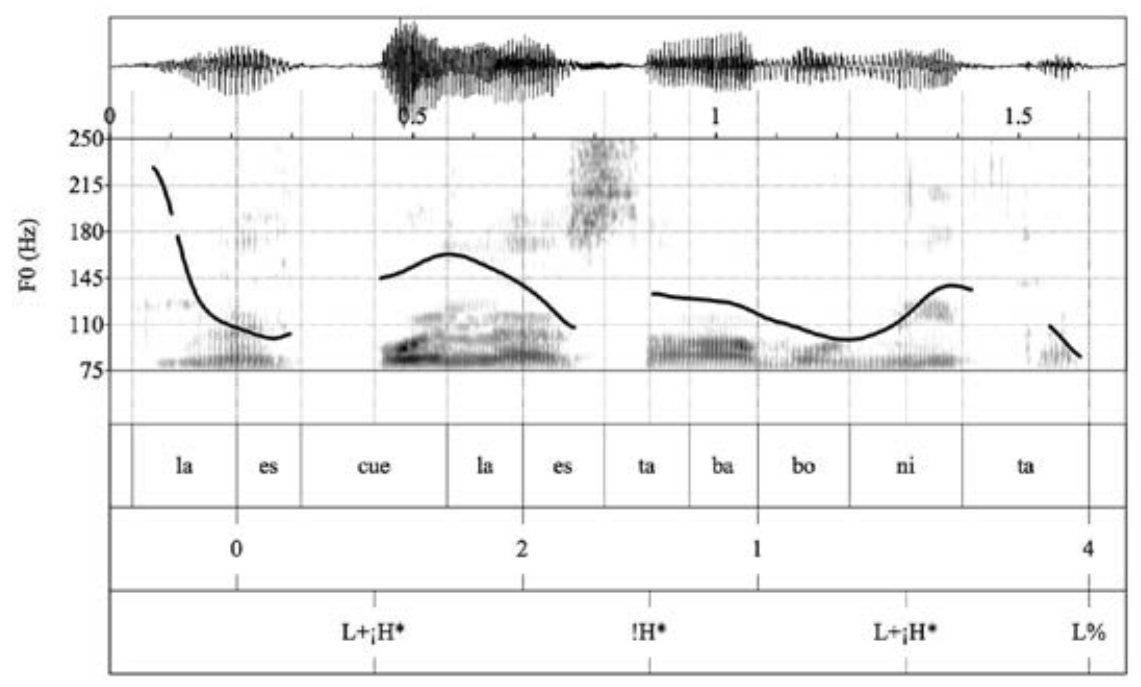

FigurA 9

Oscilograma, espectrograma y curva melódica del enunciado

Quiero mandarinas, producido por una mujer, grupo de edad correspondiente a adultos, nivel de instrucción alto

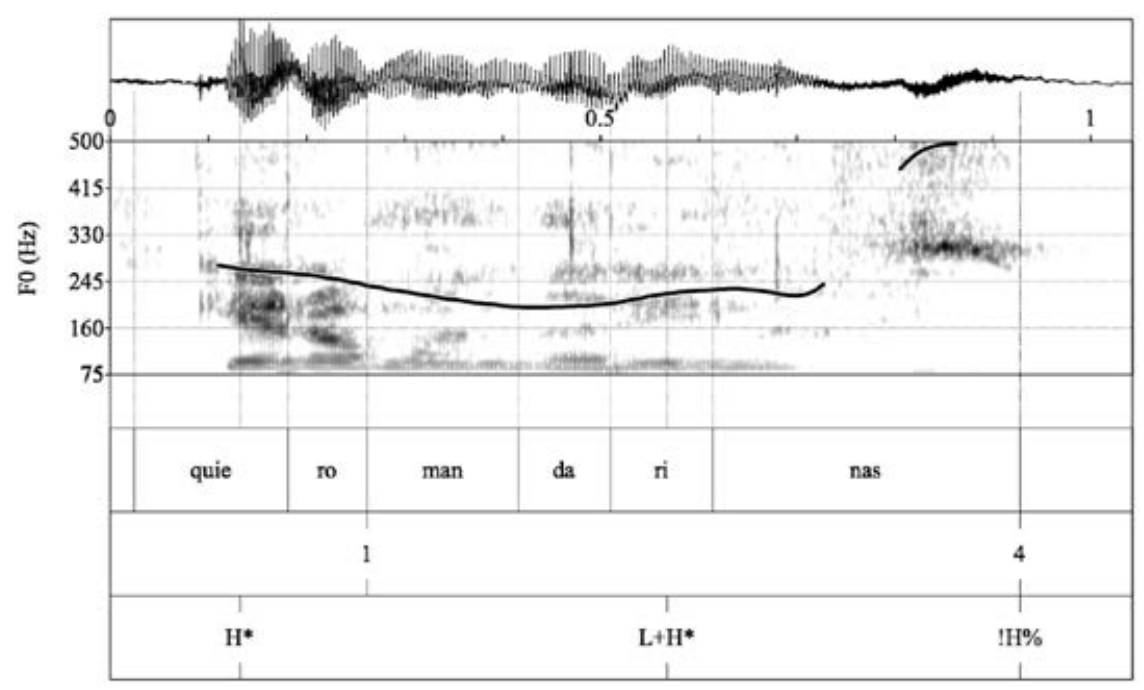

Nueva Revista de Filología Hispánica (NRFH), LXVII, 2019, núm. 1, 41-76

ISSN 0185-0121; e-ISSN 2448-6558; DOI: 10.24201/nrfh.v67i1.3464 
La diferencia en los datos de Tuxtla atiende a elementos locales de la curva melódica; en este caso, a la realización de acentos tonales alineados en la sílaba tónica en posición prenuclear.

En los datos del material prenuclear llama la atención la frecuencia y porcentaje de realización de acentos tonales $\mathrm{L}+\mathrm{H}^{*}$ -alineamiento temprano del pico nuclear-, pues, como se mencionó anteriormente, para datos del español mexicano se ha registrado en variedades en situación de contacto (Orozco 2017; Olivar en preparación). También se ha documentado en el español yucateco (Michnowicz \& Barnes 2013), asociado con vernacularidad y el grado de control en los datos (Mendoza $e t$ $a l$. 2016). En el caso de los enunciados de Tuxtla Gutiérrez que se analizan en este trabajo, no se incluyen datos de hablantes bilingües o en situación de contacto de lenguas en un momento actual, de tal manera que el alineamiento temprano podría relacionarse con otros factores sociales y/o lingüísticos. En este orden de ideas, se presentan las Tablas 11, 12 y 13 con la distribución del alineamiento de los acentos tonales y los factores sociales de edad, género y nivel de instrucción.

TABLA 11

Alineamiento del primer pico tonal y grupo de edad $(N=300)$

\begin{tabular}{lcc}
\hline \multicolumn{1}{c}{ Grupo } & $\begin{array}{c}\text { Alineamiento en tónica } \\
(F y \text { porcentaje) }\end{array}$ & $\begin{array}{c}\text { Alineamiento en postónica } \\
(\text { Fy porcentaje) }\end{array}$ \\
\hline Jóvenes & $81(81 \%)$ & $19(19 \%)$ \\
Adultos & $92(92 \%)$ & $8(8 \%)$ \\
Mayores & $69(69 \%)$ & $31(31 \%)$ \\
Total & $242(80.7 \%)$ & $58(19.3 \%)$ \\
\hline
\end{tabular}

TABLA 12

Alineamiento del primer pico tonal y género $(N=300)$

\begin{tabular}{lcc}
\hline \multicolumn{1}{c}{ Género } & $\begin{array}{c}\text { Alineamiento en tónica } \\
(\text { Fy porcentaje })\end{array}$ & $\begin{array}{c}\text { Alineamiento en postónica } \\
(\text { F y porcentaje })\end{array}$ \\
\hline Hombre & $118(78.7 \%)$ & $32(21.3 \%)$ \\
Mujer & $124(82.7 \%)$ & $26(17.3 \%)$ \\
Total & $242(80.7 \%)$ & $58(19.3 \%)$ \\
\hline
\end{tabular}


TABLA 13

Alineamiento del primer pico tonal y nivel de instrucción $(N=300)$

\begin{tabular}{ccc}
\hline $\begin{array}{c}\text { Nivel de } \\
\text { instrucción }\end{array}$ & $\begin{array}{c}\text { Alineamiento en tónica } \\
(\text { Fy porcentaje) }\end{array}$ & $\begin{array}{c}\text { Alineamiento en postónica } \\
(\text { Fy porcentaje) }\end{array}$ \\
\hline Alto & $136(75.6 \%)$ & $44(24.4 \%)$ \\
Bajo & $106(88.3 \%)$ & $14(11.7 \%)$ \\
Total & $242(80.7 \%)$ & $58(19.3 \%)$ \\
\hline
\end{tabular}

La distribución del alineamiento del acento tonal por grupos de edad indica que el conformado por adultos (35 a 54 años) concentra la mayor frecuencia y porcentaje de acentos tonales con pico alineado en la sílaba tónica. Por el contrario, se observa una disminución de esta realización en los datos de los grupos de edad integrados por los jóvenes y mayores. En lo que respecta al alineamiento en la sílaba postónica, la mayor cantidad de ocurrencias se concentra en las emisiones del grupo de edad atinente a mayores, seguido por el de los jóvenes.

En relación con el género, los porcentajes muestran una distribución semejante de ocurrencias en los datos de hombres y mujeres. La diferencia en el alineamiento en la sílaba tónica es de $4 \%$ a favor de los datos producidos por mujeres, y esta misma diferencia se observa en los datos con alineamiento en la postónica, con mayoría en las emisiones de los hombres. El último factor, nivel de instrucción, revela el mayor porcentaje de alineamiento en la sílaba tónica en las emisiones de los informantes de nivel de instrucción bajo; sin embargo, en los datos del nivel de instrucción alto se muestra un elevado porcentaje de ocurrencias de alineamiento temprano. Esta distribución de datos podría apoyar la propuesta del alineamiento del primer pico tonal como un rasgo que distingue a la variedad de Tuxtla Gutiérrez.

Para comprobar la posible influencia de los distintos factores sociales y estilísticos sobre el prealineamiento, se llevó a cabo un análisis estadístico con Goldvarb (Sankoff et al. 2012). El análisis binomial de ascenso y descenso seleccionó el grupo de edad correspondiente a adultos (0.720) y el nivel de instrucción bajo (0.638) como los factores que favorecen el alineamiento en la sílaba tónica (significatividad $=0.006$ ). El grado de control sobre los datos no fue seleccionado en esta prueba estadística, contra- 
rio a lo que ocurre en la realización del acento nuclear bitonal, en que el menor grado de control favorece la forma bitonal.

TABLA 14

Alineamiento del primer pico tonal en sílaba tónica (prealineamiento)

\begin{tabular}{cc}
\hline Edad & Nivel de instrucción \\
\hline Jóvenes: 0.472 & Alto: 0.407 \\
Mayores: 0.313 & Bajo: 0.638 \\
Adultos: 0.710 & \\
\hline
\end{tabular}

Log. Verosimilitud $=-134.208 ;$ Significatividad $=0.006$.

Líneas arriba se mencionó que el alineamiento temprano del pico tonal es un rasgo que también se ha documentado en la variedad de Mérida, Yucatán. En la investigación de Mendoza et al. (2016), el análisis estadístico seleccionó el grupo de edad concerniente a adultos y mayores como un factor que propicia el alineamiento temprano en enunciados aseverativos. Llama la atención que la estratificación social de este rasgo en el grupo de edad mencionado sea similar a la que se presenta en Tuxtla. En este sentido, se podría sugerir que las dos variedades -del sur del país- comparten este rasgo prosódico, el cual las distinguiría de la variedad de la Ciudad de México (Altiplano central) con la realización del pico tonal desplazado.

En relación con los factores lingüísticos, en este trabajo sólo se han contemplado los enunciados de foco amplio, y por lo tanto se asumiría que el factor de focalización en el pretonema no influye en la realización del prealineamiento. No obstante, en futuras investigaciones se podría profundizar en la semántica y pragmática de los enunciados obtenidos en las entrevistas sociolingüísticas. Asimismo, se podría incorporar el papel de la expresividad del hablante como una variable en la realización de los acentos tonales prealineados ${ }^{15}$. Además, aunque el factor de estilo de habla no fue seleccionado en el análisis estadístico para el prealineamiento, es posible preguntarse si el tipo de prueba puede dar lugar a una focalización o tematización

15 Para el caso de la Ciudad de México, Martín Butragueño (2016) reporta en datos de habla espontánea -y con una base estadística- la realización de picos tonales tempranos (o prealineados) asociados con la expresividad de los enunciados. 
en el pretonema. Estos puntos constituyen una base para futuras líneas de investigación.

Las configuraciones nucleares y prenucleares, en conjunto, pueden dar cuenta de las diferencias prosódicas entre distintas variedades del español -en el nivel fonético, en una primera etapa. La perspectiva de análisis en el eje de estratificación social, y en el geolingüístico, busca constituir un aporte para la elaboración de una dialectología entonativa o geoprosodia del español de México.

\section{CONCLUSIONES PRELIMINARES Y LÍNEAS DE TRABAJO} PARA EL FUTURO

El panorama de las configuraciones nucleares y prenucleares mostrado en este trabajo permite mencionar algunas tendencias: $i$ ) una característica de los enunciados aseverativos en esta variedad del español es el prominente descenso que se registra entre el primer pico tonal y el resto del material prenuclear; ii) dicho movimiento, en conjunto con la forma del acento nuclear $\mathrm{L}+\left({ }_{i}\right) \mathrm{H}^{*}$-y el valor del ascenso superior a 3 st-, además del iii) alineamiento temprano del primer pico tonal, constituyen tres rasgos prosódicos que distinguen a esta variedad del español. El alineamiento temprano es un rasgo que comparte con la variedad de Mérida, Yucatán y, a la vez, con las diferencias de la variedad de la Ciudad de México.

Por lo demás, se sugiere una propuesta de perfil social de los hablantes que favorecen las configuraciones tonales características de la variedad de Tuxtla Gutiérrez: $i$ ) el alineamiento temprano del primer acento tonal -prealineamiento- es favorecido por el grupo de edad correspondiente a adultos y el nivel de instrucción bajo; ii) el acento nuclear bitonal es favorecido por los hombres. Otro factor significativo es el tipo de prueba -mayor o menor grado de control en los datos- que asocia la mayor espontaneidad (o menor grado de control) de los datos con el acento nuclear bitonal $\mathrm{L}+(i) \mathrm{H}^{*}$, diferente al descenso en el acento nuclear $\left(\mathrm{L}^{*}\right)$ documentado en los enunciados aseverativos en otras variedades del español. Respecto al grado de control de los datos en las distintas pruebas de elicitación, se podría sugerir que los acentos nucleares bitonales en esta variedad del español emergen en los contextos de menor control de los datos -mayor espontaneidad-y que éstos se neutralizan 
o se adaptan a los patrones de la variedad del centro-Ciudad de México- en contextos más controlados.

Un punto sobre el que se puede reflexionar es el de la elicitación de enunciados con tareas de completamiento discursivo y con lectura de enunciados. Ambas pruebas, que implican un mayor grado de control sobre los datos, tienen como limitante la posible producción de respuestas poco naturales y focalizaciones que pueden influir en las configuraciones tonales. En el caso del alineamiento temprano que se propone en este trabajo, éste se podría propiciar por el factor de focalización en posición prenuclear; sin embargo, al registrarse en los tres grupos de edad y en los tres diferentes estilos de habla, se sugiere como una tendencia recurrente en esta variedad del español. En este sentido, la integración de los tres estilos de habla -o grados de control sobre los datos- ha permitido obtener un panorama más amplio de la variación en los enunciados aseverativos de foco amplio en los datos de Tuxtla. No obstante, se reconoce la necesidad de ampliar la elicitación de datos a situaciones comunicativas reales -es decir en interacciones cotidianas-que permitan comprobar la realización de las configuraciones tonales descritas en este trabajo.

El análisis estadístico ha proporcionado testimonios de los factores sociales que favorecen el alineamiento temprano y el acento nuclear bitonal. Una línea de investigación para el futuro es la evaluación de las respuestas del cuestionario sociológico, con el fin de determinar la influencia de las actitudes lingüísticas e integración en la comunidad de habla en la producción de las configuraciones tonales. En una primera revisión de datos, las respuestas por grupo de edad mostraron que el de los jóvenes es el único que mencionó la entonación (o "el acento") como criterio para distinguir formas regionales del español, e incluso trazaron zonas dentro del propio estado. También reconocieron la importancia del uso correcto de la lengua. Por el contrario, los adultos otorgan menor relevancia a este parámetro y, además, consideran la variedad propia como la mejor. En el caso de los informantes mayores no hay una evaluación positiva o negativa hacia la variedad local (sólo en un caso se asume como "la peor"), pero es el grupo que estima con puntuación más alta los valores locales. Así, se podría inquirir si los jóvenes que identifican el rasgo de la entonación como determinante en las zonas regionales neutralizan o no favorecen los rasgos prosódicos de su propia variedad. Esta cuestión se podría 
discutir ampliamente con la evaluación en conjunto de las respuestas del cuestionario sociológico.

Una línea de investigación que se podrá considerar es la interacción de distintos rasgos lingüísticos como apoyo para la indización (en términos de Eckert 2008). Para la zona de Chiapas, uno de los rasgos lingüísticos más sobresalientes es la presencia del voseo, que dialectológicamente ha distinguido a esta zona. Al respecto, el análisis sociolingüístico de Oseguera (2013) demuestra que los factores género y edad -en conjunto con factores pragmáticos- influyen en la producción del voseo, y son las personas mayores, seguidas por el grupo de jóvenes, quienes favorecen este rasgo, no así el grupo de mayores de treinta y menores de cincuenta años. De alguna manera, esta tendencia es inversa a la que se observa en el análisis de las configuraciones tonales en esta investigación. Así, una posible hipótesis plantearía que si los hablantes más jóvenes y adultos favorecen el voseo (como un rasgo de identidad), los adultos se valdrían de los recursos prosódicos para este fin. En este sentido, una de las líneas de trabajo para el futuro es analizar la manera en que los distintos rasgos lingüísticos -prosódicos, morfológicos y sintácticos- que caracterizan a esta comunidad se complementan en la construcción de identidad local.

Finalmente, en este trabajo se ha buscado contribuir a la hipótesis geoprosódica del español de México. A partir de la caracterización de los rasgos prosódicos, ha sido posible dar cuenta de las similitudes entre las variedades de Tuxtla Gutiérrez y Mérida, Yucatán -ambas caracterizadas como zonas dialectales aisladas. Se observan diferencias en la configuración nuclear, que seguiría marcando la zona de Yucatán como una variedad no descendente (terminación $\mathrm{L}^{*} \mathrm{H} \%$ o ! H* M\%), en contraste con el descenso documentado en Tuxtla. Sin embargo, también se observa el rasgo de alineamiento temprano, que se registra en ambas variedades y difiere a la vez de la realización registrada en el Altiplano central (específicamente de la Ciudad de México). En consecuencia, se sugiere la relevancia de la configuración prenuclear como un rasgo pertinente para advertir de las diferencias entre variedades del español. Por lo demás, la información que aporta la entonación de los enunciados aseverativos en la variedad de Tuxtla Gutiérrez debe complementarse con la descripción de otros tipos enunciativos, más correlatos prosódicos -duración, fraseo, etc.-, con el propósito de seguir aportando datos a una futura dialectología entonativa de México. 


\section{REFERENCIAS}

Armstrong, Meghan E. 2010. "Puerto Rican Spanish intonation", en Transcription of intonation of the Spanish language. Eds. Pilar Prieto \& Paolo Roseano, Lincom Europa, München, pp. 155-190.

Baird, Brandon O. 2015. "Pre-nuclear peak alignment in the Spanish of Spanish-K'ichee' (Mayan) bilinguals", en Selected proceedings of the 6th Conference on laboratory approaches to Romance phonology. Eds. Erik W. Willis et al., Cascadilla Proceedings Project, Somerville, MA, pp. 163-174.

Beckman, M., Manuel Díaz-Campos, J.T. Mcgory \& T.A Morgan 2002. "Intonation across Spanish, in the tones and break indices framework", Probus, 14, pp. 9-36.

Boersma, Paul \& David Weenink 2016. Praat. Versión 6.0.16, Universiteit Amsterdam, Amsterdam.

ColAntONI, LAURA 2011. "Laboratory approaches to sound variation and change", en The handbook of Hispanic sociolinguistics. Ed. Manuel DíazCampos, Blackwell Publishing, Oxford, pp. 9-35.

De-la-Mota, Carme, Pedro Martín Butragueño \& Pilar Prieto 2010. "Mexican Spanish intonation", en Transcription of intonation of the Spanish language. Eds. Pilar Prieto \& Paolo Roseano, Lincom Europa, München, pp. 319-350.

Eckert, Penelope 2008. "Variation and indexical field", Journal of Sociolinguistics, 12, pp. 453-476.

Estebas Vilaplana, Eva y Pilar Prieto 2008. "La notación prosódica del español: una revisión del Sp_ToBI”, Estudios de Fonética Experimental, 17, pp. 263-283.

Frota, Sonia \& Pilar Prieto (eds.) 2015. Intonation in Romance, Oxford University Press, Oxford.

Gil Burgoin, Carlos Ivanhoe 2011. El español del municipio de La Paz: variación fónica y entonativa, tesis, Escuela Nacional de Antropología e Historia, México.

Gutiérrez-Bravo, Rodrigo 2008. "La identificación de los tópicos y los focos”, Nueva Revista de Filología Hispánica, 56, pp. 362-401.

Henríquez Ureña, Pedro 1921. "Observaciones sobre el español de América”, Revista de Filología Española, 8, pp. 357-390.

HenríQuez Ureña, Pedro 1938. El español en Méjico, los Estados Unidos y la América Central, Universidad de Buenos Aires, Buenos Aires. $(B D H, 4)$.

Hualde, José Ignacio \& Pilar Prieto 2015. "Intonational variation in Spanish: European and American varieties", en Intonation in Romance. Eds. Sonia Frota \& Pilar Prieto, Oxford University Press, Oxford, pp. 350-391.

INALI 2008. Catálogo de las lenguas indígenas nacionales. Variantes lingüísticas de México con sus autodenominaciones y referencias geoestadísticas, Instituto Nacional de Lenguas Indígenas, México.

INEGI 2010. Chiapas. Información por entidad, http://www.cuentame. inegi. org.mx [consultado el 20 mayo de 2017].

LADD, D.R. 2008. Intonational phonology, Cambridge University Press, Cambridge. 
LIPSKI, JoHN M. 2011. "Socio-phonological variation in Latin American Spanish", en The handbook of Hispanic sociolinguistics. Ed. Manuel Díaz-Campos, Blackwell Publishing, Oxford, pp. 72-97.

Lope Blanch, Juan M. 1996. "México", en Manual de dialectología hispánica. El español de América. Dir. Manuel Alvar, Ariel, Barcelona, pp. 81-89.

Martín Butragueño, Pedro 2004. "Configuraciones circunflejas en la entonación del español mexicano", Revista de Filología Española, 84, pp. 347-373.

Martín Butragueño, Pedro 2006. "Proyección sintáctico-discursiva de la entonación circunfleja mexicana”, en El español en América. Diatopia, diacronía e historiografía. Homenaje a José G. Moreno de Alba en su 65 aniversario. Ed. Concepción Company, Universidad Nacional Autónoma de México, México, pp. 35-63.

Martín Butragueño, Pedro 2011. "La estratificación sociolingüística de la entonación circunfleja mexicana”, en Realismo en el análisis de corpus orales. Primer coloquio de cambio y variación lingüistica. Ed. Pedro Martín Butragueño, El Colegio de México, México, pp. 93-121.

Martín Butragueño, Pedro 2014. Fonología variable del español de México. T. 1: Procesos segmentales, El Colegio de México, México.

Martín Butragueño, Pedro 2014a. "La división dialectal del español mexicano", en Historia sociolingüistica de México. T. 3: Espacio, contacto y discurso político. Eds. Rebeca Barriga y Pedro Martín Butragueño, El Colegio de México, México, pp. 1353-1407.

Martín Butragueño, Pedro 2014b. "Prosodia fonética de enunciados representativos e interrogativos absolutos: elementos locales y globales", Estudios de Fonética Experimental, 23, pp. 125-202.

Martín Butragueño, Pedro 2016. “«A veces lloro mis lágrimas». Acercamiento multivariable a la prosodia de los actos de habla expresivos en el español de México”, Estudios de Lingüistica Aplicada, 34, 63, pp. 59-102.

Martín Butragueño, Pedro 2017. "Contacto dialectal entonativo. Estudio exploratorio”, en Estudios de variación geolingüistica. Eds. Leonor Orozco y Alonso Guerrero Galván, Instituto Nacional de Antropología e Historia, México, pp. 139-168.

Martín Butragueño, Pedro en prensa. "Historia de dos medidas: contacto entonativo en la Ciudad de México”, en Contacto lingüistico. Eds. Julio Serrano y María Ángeles Soler, Universidad Nacional Autónoma de México, México.

Martín Butragueño, Pedro, Erika Mendoza y Leonor Orozco (coords.) en preparación. Corpus oral del español de México (COEM), en http:/ / lef. colmex.mx [consultado el 1 de agosto de 2017].

Martínez Celdrán, Eugenio y Ana M. Fernández Planas (coords.) 20032018. AMPER, Atlas multimèdia de la prosòdia de l'espai Romànic, http:/ / stel.ub.edu/ labfon/ amper/ cast/ index_internacional.html [consultado el 10 de marzo de 2018].

Mendoza Vázquez, Erika 2014. La impresión de un tono: estudio sociolingüistico de la entonación de Cuapiaxtla, Tlaxcala, tesis, El Colegio de México, México.

Mendoza, Erika, Leonor Orozco y Pedro Martín Butragueño 2016. "Nueva visita al prealineamiento del español yucateco de Mérida", 8th 
International workshop of Spanish sociolinguistics, Universidad de Puerto Rico, Río Piedras.

Michnowicz, Jim \& Hilary Barnes 2013. "A sociolinguistic analysis of prenuclear peak alignment in Yucatan Spanish”, en Selected proceedings of the 15th Hispanic linguistics symposium. Eds. C. Howe, S.E. Blackwell \& Lubbers Quesada, Cascadilla Proceedings Project, Somerville, MA, pp. 221235.

Montellano Moreno, Uriel 2017. Entonación de enunciados declarativos e interrogativos en el habla de Monterrey, tesis, Escuela Nacional de Antropología e Historia, México.

Moreno Fernández, Francisco 2009. La lengua española en su geografía, Arco/Libros, Madrid.

Murrieta, Laura 2016. Análisis experimental del umbral de percepción entonativa en el español del centro de México, tesis, Universidad Nacional Autónoma de México, México.

Navarro Tomás, Tomás 1944. Manual de entonación española, Hispanic Institute in the United States, New York.

Nespor, Marina e Irene Vogel 1994. La prosodia, Visor, Madrid.

Olivar Espinosa, Stefany en preparación. Algunos aspectos en el estudio de la entonación del español en contacto con el náhuatl de San Miguel "Canoa”, Puebla, tesis, El Colegio de México, México.

O'Rourke, Erin 2005. Intonation and language contact: A case study of two varieties of Peruvian Spanish, tesis, University of Illinois at Urbana-Champaign.

Orozco, LeOnor 2016. "Aproximación a la entonación de enunciados declarativos en Guadalajara”, en Estudios de Lingüistica Aplicada, 34, 63, pp. 13-35.

Orozco, LeOnor 2017. "Entonación en enunciados declarativos: estudio de caso en la comunidad de Misión de Chichimecas", en Primer encuentro del Seminario de Prosodia: avances y perspectivas, Universidad Autónoma de Querétaro, Querétaro.

OSEguera, ANDRÉs 2013. “¿Idiay pue vos?”: aproximación sociolingüística al voseo en Tuxtla Gutiérrez, Chiapas, tesis, Escuela Nacional de Antropología e Historia, México.

Pamies Bertrán, A., Ana María Fernández Planas, Eugenio Martínez Celdrán, A. Ortega Escandell y M. Amorós Céspedes 2001. "Umbrales tonales en español peninsular”, en Actas del II Congreso nacional de fonética experimental. Ed. María Cuenca Villarin, Universidad de Sevilla, Sevilla, pp. 272-278.

Pierrehumbert, Janet 1980. The phonetics and phonology of English intonation, tesis, Massachusetts Institute of Technology, Cambridge.

Prieto, Pilar y Paolo Roseano 2009-2013. Atlas interactivo de la entonación del español, http://prosodia.upf.edu/atlasentonacion/ [consultado el 1 de agosto de 2017].

Prieto, Pilar \& Paolo Roseano 2010. Transcription of intonation of the Spanish language, Lincom Europa, München.

Quilis, Antonio 1993. Tratado de fonología y fonética españolas, Gredos, Madrid. 
Sankoff, David, Sali A. Tagliamonte \& E. Smith 2012. Goldvarb Lion. A multivariate analysis application, http://individual. utoronto.ca/ tagliamonte/goldvarb.htm [consultado el 1 de agosto de 2017].

Serrano, Julio ms. ¿Cuántos dialectos del español existen en México? Un ensayo de dialectología perceptual, lef.colmex.mx [consultado el 30 de mayo de 2017].

Sosa, Juan Manuel 1999. La entonación del español. Su estructura fónica, variabilidad y dialectología, Cátedra, Madrid.

Velásquez Upegui, Eva 2013. Entonación del español hablado en Colombia, tesis, El Colegio de México, México.

Willis, Erik W. 2005. "Tonal levels in Puebla Mexico Spanish declaratives and absolute interrogatives", en Theoretical and experimental approaches to Romance linguistics. Eds. Randall Gess \& Ed Rubin, John Benjamins, Amsterdam, pp. 351-363.

Willis, ERIK W. 2010. "Dominican Spanish intonation", en Transcription of intonation of the Spanish language. Eds. Pilar Prieto \& Paolo Roseano, Lincom Europa, München, pp. 123-153. 